\title{
What is new from the Canadian Paediatric Society Committee on Infectious Diseases and Immunization?
}

\author{
Joan Robinson MD
}

\begin{abstract}
Dublications from the Canadian Paediatric Society (CPS) 1 Committee on Infectious Diseases and Immunization aim to provide practical advice for family physicians and pediatricians regarding the prevention and management of infectious diseases. Position statements represent CPS policies and contain recommendations, while practice points are primarily educational. The present article will summarize recent publications, all of which can be accessed online at www.cps.ca/documents/authors-auteurs/ infectious-diseases-and-immunization-committee.
\end{abstract}

\section{Prevention and management of neonatal herpes simplex virus} infections (1)

Prevention of neonatal herpes simplex virus (HSV) remains a vital goal because the clinical presentation is nonspecific and, thus, therapy is commonly delayed, leading to mortality and long-term morbidity. It remains standard practice in Canada to perform a caesarean section (CS) for women with visible genital HSV lesions at the time of delivery to prevent neonatal HSV infection. This is a controversial policy for women with recurrent genital HSV because it is estimated that 1580 CSs must be performed to prevent one case of neonatal HSV (2). Women with a history of genital HSV are commonly prescribed antivirals from 36 weeks' gestation until delivery. This decreases the need for CS but does not completely prevent neonatal HSV infection (3).

The major limitation to these strategies is that the vast majority of genital HSV manifests as subclinical shedding. Therefore, most women with genital HSV are not diagnosed and, therefore, are not offered antivirals or a CS. Approximately $10 \%$ of asymptomatic and $20 \%$ of symptomatic adults seropositive for HSV-2 exhibit genital shedding of virus on a given day, as detected by polymerase chain reaction (PCR) (4). A significant percentage of pregnant women in Canada have antibodies to HSV-2 (10\% in an Ontario study from 2000 to 2001 [5] and 17\% in a British Columbia study from 1999 [6]). Genital HSV-1 also contributes to neonatal HSV; the Canadian Paediatric Surveillance Program found that $63 \%$ of neonatal HSV in 2000 to 2003 was due to HSV-1 (7). More than one-half of genital HSV in British Columbia is now due to HSV-1 (8). It can be concluded that a significant proportion of Canadian infants are at risk for neonatal HSV due to exposure to HSV-1 or HSV-2 during the birth process.

Because neonatal HSV can result in severe developmental delay or death, an analysis showed that it may be cost effective in Canada to screen couples for HSV type-specific discordance to recognize the risk for, and potentially prevent, first-episode genital HSV during pregnancy (9). This analysis assumes monogamy and compliance with recommendations for abstinence, condom use or antiviral prophylaxis for a discordant male partner thoughout the pregnancy, which may be difficult to achieve. Further study is required before implementation.

Fortunately, neonatal HSV remains rare in Canada, presumably because passive maternal antibodies are highly effective in preventing neonatal disease; thus, risk is only high with maternal first-episode genital HSV at the time of delivery. In fact, women with recurrent genital HSV have a $<1 \%$ risk of having an infant with neonatal HSV if they have a vaginal delivery, while those with first-episode primary
HSV have a risk of approximately $40 \%$ (10). The main revision in the CPS position statement is that it provides algorithms for management of infants born to women with genital HSV. One controversial point is that the statement recommends use of type-specific serology when women with no history of genital HSV have a delivery other than an elective CS in the face of active genital lesions. Often, such women have recurrent genital HSV disease with unrecognized previous episodes. It is recommended that their infants be treated with intravenous acyclovir pending the results of type-specific serology. Such serology is useful because it takes a median of three weeks to develop type-specific antibodies (11). If the mother has serological evidence of recurrent HSV, the acyclovir can be stopped, while if she has first-episode primary or nonprimary HSV, acyclovir should be continued for 10 days. Time will tell whether the turn-around time for type-specific serology makes this a practical recommendation.

Early treatment of neonatal HSV improves the prognosis. HSV is likely more common now than bacterial meningitis in infants admitted from home in the first month of life. The statement encourages clinicians to consider the diagnosis of neonatal HSV in infants with possible sepsis and outlines when to consider empirical acyclovir. One difficulty is that infants with possible sepsis are commonly started on acyclovir without appropriate specimens being obtained (12); thus, the statement encourages communication with the local laboratory about which specimens to submit. Use of PCR on all types of specimens for diagnosis of HSV is now widespread. There is a need for more data regarding the sensitivity and specificity of PCR testing on mucous membrane specimens from potentially exposed infants who remain asymptomatic and on blood from infants with possible disseminated neonatal HSV.

Guidelines for the management of suspected and confirmed bacterial meningitis in Canadian children older than one month of age (13)

A common situation in pediatrics is that residents make it into their second year without having seen a case of proven bacterial meningitis. Routine infant immunization programs for pneumococcus and Haemophilus influenzae b (Hib) have resulted in this remarkable progress. The incidence of meningococcal meningitis can vary widely from year to year; however, there has been minimal serogroup $\mathrm{C}$ disease in Canada in any age group since all jurisdictions introduced routine programs, with some starting at two months of age and others at 12 months of age. The United States has witnessed a similar decrease in the incidence of serogroup $\mathrm{C}$ disease in all age groups with only an adolescent immunization program.

Other than continuing remarkable decreases in the incidence of bacterial meningitis, not much has changed between the 2007 and the 2014 CPS position statements on bacterial meningitis. Empirical treatment with vancomycin and either cefotaxime or ceftriaxone is recommended for previously well children. The statement recommends that vancomycin can sometimes be stopped in the face of negative cultures even if they were obtained after antibiotics were given, especially if the local incidence of pneumococcus resistant to thirdgeneration cephalosporins is very low. Given the unclear evidence on

University of Alberta and Stollery Children's Hospital, Edmonton, Alberta

Correspondence: Dr Joan Robinson, University of Alberta and Stollery Children's Hospital, 3-556 ECHA 11405-87 Avenue, Edmonton, Alberta

T6G 1C9. Telephone 780-248-5540, fax 888-790-1176, e-mail jr3@ualberta.ca

open Access

This open-access article is distributed under the terms of the Creative Commons Attribution Non-Commercial License (CC BY-NC) (http:// creativecommons.org/licenses/by-nc/4.0/), which permits reuse, distribution and reproduction of the article, provided that the original work is properly cited and the reuse is restricted to noncommercial purposes. For commercial reuse, contact support@pulsus.com 
use of corticosteroids for children with non-Hib bacterial meningitis, the statement is noncommittal.

\section{Clostridium difficile in pediatric populations (14)}

Although the incidence of Clostridium difficile infection appears to have increased in some centres, it is not clear whether this is a true increase or the result of increased testing or more sensitive tests. In a 2008 to 2012 retrospective study involving children hospitalized at the Hospital for Sick Children in Toronto (Ontario), there was no increased incidence over the four years of the study. Only five of 299 cases led to intensive care unit admission. There were no colectomies and the only death was a child who also had Enterobacter sepsis (15). Clearly, children tolerate $C$ difficile colitis better than adults.

The 2000 CPS position statement on C difficile was updated in 2014 (14). The main points are that mild disease is often self-resolving and that retesting should never be performed if the child is clinically improved. Metronidazole remains the treatment of choice for all but severe illness.

\section{Immunization for meningococcal serogroup B: What does the} practitioner need to know? (16)

There were a mean of 194 cases of invasive meningococcal disease per year in Canada from 2007 to 2011. A mean of 111 of these were serogroup B, of which 22 were in infants $<6$ months of age and 21 were in children one through four years of age (17). The fourcomponent vaccine 4CMen B or Bexsero (Novartis Pharmaceuticals Canada, Inc) contains the subcapsular proteins neisserial heparinfinding antigen, factor $\mathrm{H}$-binding protein, neisserial adhesion $\mathrm{A}$ and Por A. This vaccine was licensed in Canada in December 2013 for children two months through 17 years of age and became available in February 2014 at a cost of $\$ 101 /$ dose. Presumed adequate antibody levels to all four components has been established after three doses in the first six months of life, two doses at 12 to 15 months of age, or two doses at 11 to 17 years of age or in adulthood. The optimal timing of booster doses is not yet clear. This vaccine results in more fever than other vaccines currently administered routinely in infancy. This is a potential issue at two months of age, when the relatively high incidence of bacterial infection often prompts a full septic work-up with any fever.

Not all serogroup B strains contain even one of the four vaccine components. A meningococcal antigen testing system has been devised to determine which components are present in sufficient titre that one would predict that $4 \mathrm{CMenB}$ would be effective against that strain. An estimated $66 \%$ of recently circulating B strains in Canada

\section{REFERENCES}

1. Allen UD, Robinson JL; Canadian Paediatric Society, Infectious Diseases and Immunization Committee. Prevention and management of neonatal herpes simplex virus infections. Paediatr Child Health 2014;19;201-6.

2. Randolph AG, Washington AE, Prober CG. Cesarian delivery for women presenting with genital herpes lesions: Efficacy, risks, and costs. JAMA 1993;270:77-82.

3. Pinninti SG, Angara R, Feja KN, et al. Neonatal herpes disease following maternal antenatal antiviral suppressive therapy: A multicenter case series. J Pediatr 2012;161:134-8.e1-3.

4. Tronstein E, Johnston C, Huang ML, et al. Genital shedding of herpes simplex virus among symptomatic and asymptomatic persons with HSV-2 infection. JAMA 2011;305:1441-9.

5. Howard M, Sellors JW, Jang D, et al. Regional distribution of antibodies to herpes simplex virus type 1 (HSV-1) and HSV-2 in men and women in Ontario, Canada. J Clin Microbiol 2003;41:84-9.

6. Patrick DM, Dawar M, Cook DA, Krajden M, Ng HC, Rekart ML. Antenatal seroprevalence of herpes simplex virus type 2 (HSV-2) in Canadian women: HSV-2 prevalence increases throughout the reproductive years. Sex Transmit Dis 2001;28:424-8.

7. Kropp RY, Wong T, Cormier L, et al. Neonatal herpes simplex virus infections in Canada: Results of a 3-year national prospective study. Pediatrics 2006;117:1955-62.

8. Gilbert M, Li X, Petric M et al. Using centralized laboratory data to monitor trends in herpes simplex virus type 1 and 2 infection in (but only $49 \%$ of strains in children $<1$ year of age) contained at least one of the four vaccine components (18).

The CPS practice point was written to inform clinicians about the $4 \mathrm{CMenB}$ vaccine, but deliberately did not make a specific recommendation about routine use because the National Advisory Committee on Immunizations (NACI) was yet to release their recommendations. With 14 different immunization schedules in Canada (10 provinces, three territories and the First Nations and Inuit Health Branch), there is sufficient confusion about the optimal schedule that the CPS attempts to align with NACI whenever possible. The NACI recommendations were recently made public and suggest use only for those at high risk for meningococcal disease, those in close contact with a case of invasive meningococcal disease caused by serogroup B, and those at risk during outbreaks caused by serogroup B or during the emergence of hyperendemic and/or hypervirulent Neisseria meningitidis strains that are predicted to be susceptible to the vaccine based on meningococcal antigen testing (17). A program targeting all individuals two months to 20 years of age in the Saguenay-Lac-StJean (Quebec) region was announced April, 2014 because this region has a higher incidence of disease than do other parts of Quebec (19).

Given the severity of invasive meningococcal disease, it is tempting to advocate for routine use of this vaccine in infancy with a catchup program for older children. However, the main barriers to this are the cost per case prevented (especially if frequent boosters are required), the presumed lack of impact on cases that occur before six months of age, and the fact that we currently have only indirect evidence that the vaccine will be effective against circulating strains.

\section{Minimizing infection risks after pediatric organ transplants: Advice for practitioners (20)}

This practice point focuses on immunizations pre- and post-transplant, immunosuppressive drugs, prophylactic antimicrobials, drug interactions and management of fever post-transplant.

\section{Working with vaccine-hesitant parents (21)}

Recent measles outbreaks in Canada have highlighted the essential role of the decisions parents make about immunizing their children in determining the number of cases that arise when a highly contagious vaccinepreventable infection is imported by a traveller. This practice point outlines that the first essential step in dealing with the parents of underimmunized children is to determine whether the child is not immunized because the parent lacks confidence in the safety of vaccines, the parent does not perceive the importance of immunization or the parent does not find it convenient to have the child immunized. Suggestions are made for addressing each possibility.

British Columbia and the changing etiology of genital herpes. Can J Public Health 2011;102;225-9.

9. Tuite AR, McCabe CJ, Ku J, Fisman DN. Projected cost-saving with herpes simplex virus screening in pregnancy: Towards a new screening paradigm. Sex Transm Infect 2011;87:141-8.

10. Brown ZA, Wald A, Morrow RA, Selke S, Zeh J, Corey L. Effect of serologic status and Cesarean delivery on transmission rates of herpes simplex virus from mother to infant. JAMA 2003;289:203-9.

11. Ashley-Morrow R, Krantz E, Wald A. Time course of seroconversion by HerpeSelect ELISA after acquisition of genital herpes simplex virus type 1 (HSV-1) or HSV-2. Sex Transmit Dis 2003;30:310-4

12. Vanderpluym C, Tawfik G, Hervas-Malo M, Lacaze-Masmonteil T, Kellner J, Robinson JL. Empiric acyclovir for neonatal herpes simplex virus infection. J Matern Fetal Neonatal Med 2012;25:278-82.

13. Le Saux N; Canadian Paediatric Society, Infectious Diseases and Immunization Committee. Guidelines for the management of suspected and confirmed bacterial meningitis in Canadian children older than one month of age. Paediatr Child Health 2014;19:141-6.

14. Allen UD; Canadian Paediatric Society, Infectious Diseases and Immunization Committee. Clostridium difficile in paediatric populations. Paediatr Child Health 2014;19:43-8.

15. Schwartz KL, Darwish I, Richardson SE, Mulvey MR, Thampi N. Severe clinical outcome is uncommon in Clostridium difficile infection in children: A retrospective cohort study. BMC Pediatrics 2014;14:28. 


\section{Robinson}

16. Robinson JL; Canadian Paediatric Society, Infectious Diseases and Immunization Committee. Immunization for meningococcal serogroup B - What does the practitioner need to know? Paediatr Child Health 2014;19:91-4.

17. NACI statement on meningococcal $B$ vaccine which is not yet on-line but hopefully will be by the time this article comes out

18. Bettinger JA, Scheifele DW, Halperin SA, et al; members of the Canadian Immunization Monitoring Program, Active (IMPACT). Diversity of Canadian meningococcal serogroup B isolates and estimated coverage by an investigational meningococcal serogroup $B$ vaccine (4CMenB).Vaccine 2013;32:124-30.
19. Santé et services social Québec. Vaccination: The best protection! $<$ www.msss.gouv.qc.ca/sujets/santepub/vaccination/index. php?accueil_en> (Accessed April 24, 2014).

20. Allen UD; Canadian Paediatric Society, Infectious Diseases and Immunization Committee. Minimizing infection risks after paediatric organ transplants: Advice for practitioners. Paediatr Child Health 2013;18:143-8.

21. MacDonald NE, Finlay JC; Canadian Paediatric Society, Infectious Diseases and Immunization Committee. Working with vaccinehesitant parents. Paediatr Child Health 2013;18:265-7. 


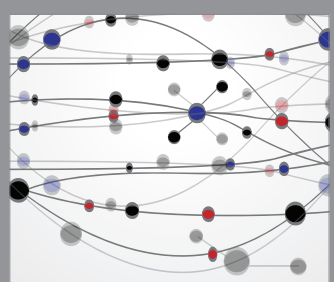

The Scientific World Journal
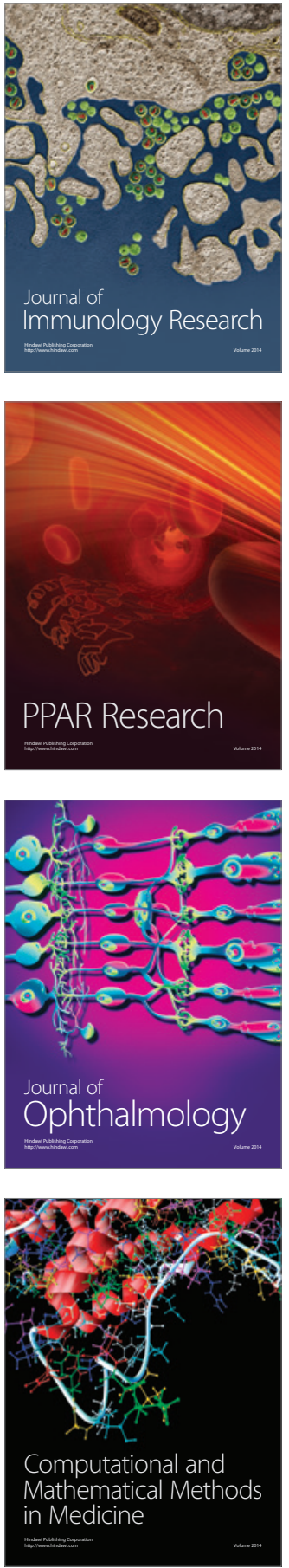

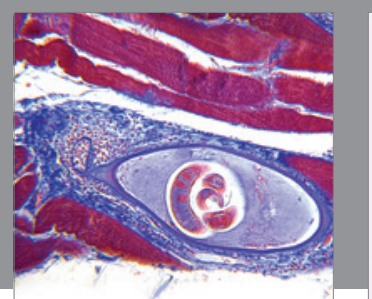

Gastroenterology Research and Practice

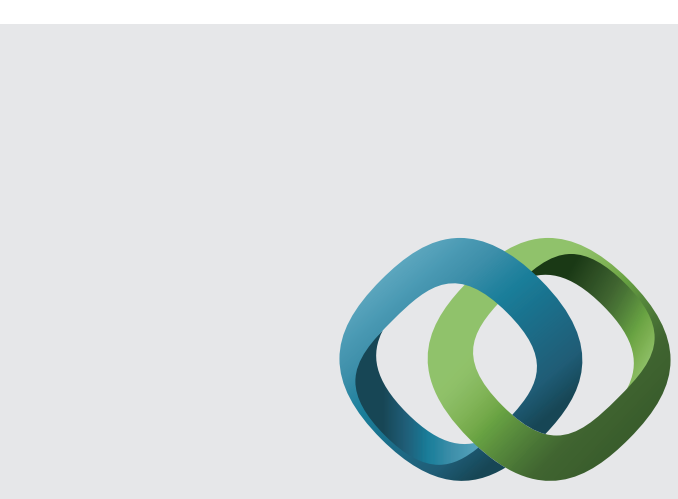

\section{Hindawi}

Submit your manuscripts at

http://www.hindawi.com
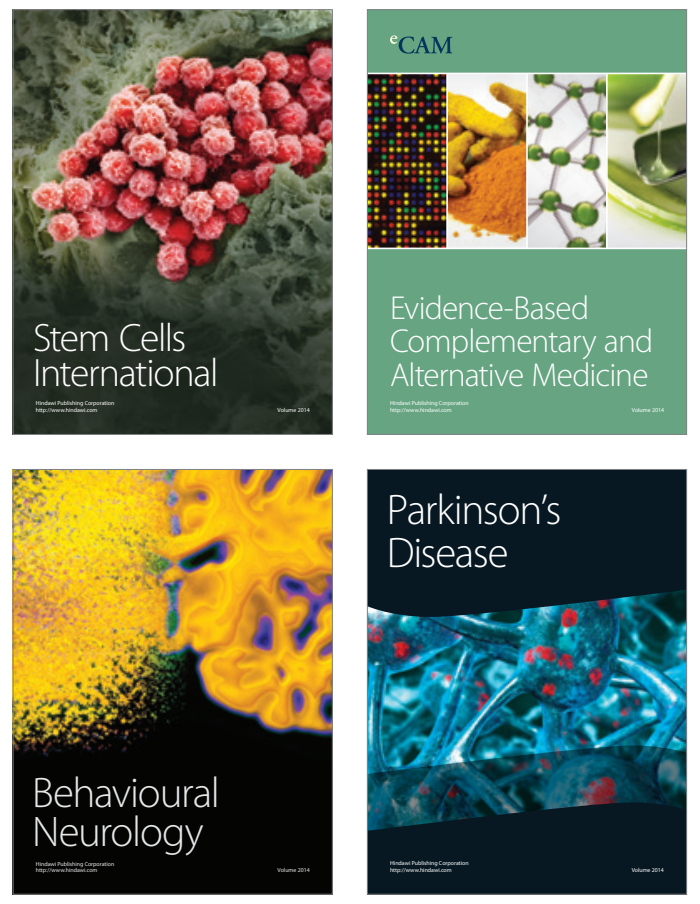
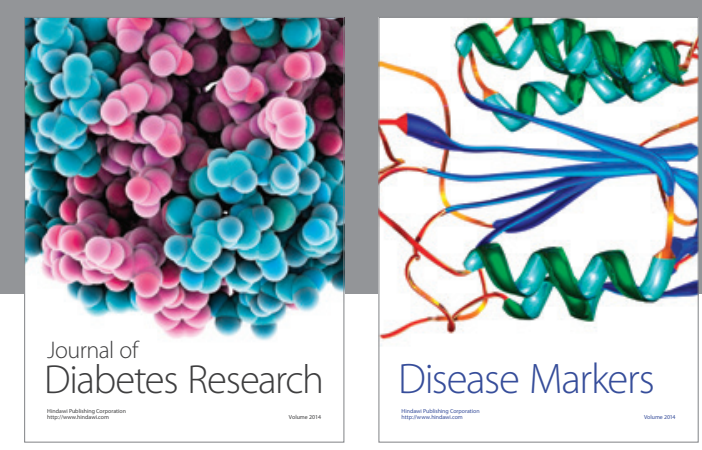

Disease Markers
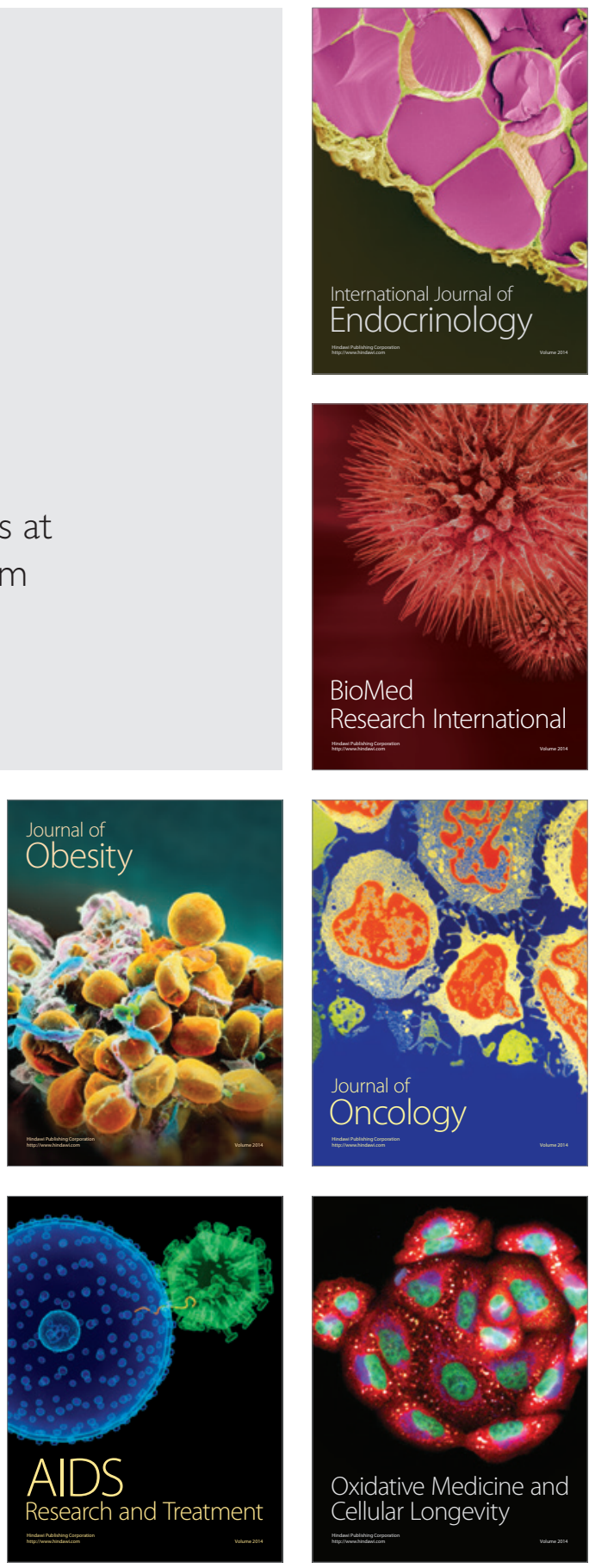